() А. І. Іванко, канд. техн. наук, доцент, А. А. Степанков, магістрант, КПІ ім. Ігоря Сікорського, Київ, Україна

\title{
ПРИСТРІЙ ДЛЯ ТРАНСПОРТУВАННЯ КНИЖКОВИХ ТА ЖУРНАЛЬНИХ БЛОКІВ У ЗОНУ ОБРІЗУВАННЯ
}

\section{В статті проведено комп'ютерне моделювання у сере- довищі SolidWorks пристрою для транспортування книжкових та журнальних блоків у зону їх обрізування.}

Ключові слова: книжково-журнальний блок; обрізування; траковий транспортер; серводвигун; траєкторія руху; сервопривод; потокова лінія.

\section{Постановка проблеми}

Швидкісні характеристики потокового виробництва книжкових та журнальних блоків постійно збільшуються. Удосконалюються засоби транспортування книжково-журнальних блоків (КЖБ) та розробляються нові безупинні способи їх обрізування [1-4]. у більшості випадків різальні модулі можуть здійснювати технологічні операції обрізування визначених частин півфабрикатів під час транспортування [5-7].

Таким чином, удосконалені модулі повинні комплектуватись високопродуктивними комбінованими механізмами, засобами відокремлення КЖБ від привертки, пристроями подачі їх в зону обрізування та виводу [8-11].

Вирішення проблеми якісного позиціювання блоків у різальній секції $€$ актуальним питанням на сьогодні.

\section{Аналіз попередніх}

\section{досліджень}

Транспортувальні пристрої дозволяють швидко підлаштову- ватись під новий формат та конструкцію модуля для обрізування КЖБ [12-14]. Однак у запропонованих засобів транспортування у зоні обрізування проблемою $€$ «висота» аркушевих матеріалів. Аркуш картону переміщується пневматичними засобами транспортування $з$ одночасним обрізуванням його визначених країв. Відповідно безупинне обрізування КЖБ в цих різальних секціях не передбачене.

\section{Мета роботи}

Проектування пристрою модульної будови для транспортування книжкових та журнальних блоків у зону їх обрізування, визначення основних технологічних характеристик процесу транспортування КЖБ.

Також метою роботи є попередній аналіз реверсивного руху півфабрикату в ланці транспортера - каретці, проведення моделювання засобами автоматизованого проектування SolidWorks

() $2018 \mathrm{p}$. 
сервопривода транспортувального модуля, що вміщує в собі ланку тракового транспортера.

\section{Результати проведеного дослідження}

Пристрій для транспортування книжкових блоків у зону їх обрізування зображено на рисунку 1. До складу пристрою входить сервопривод, механізм каретки та механізм притиску книжкового блока.

Конструкція каретки вміщує в собі нерухому раму 1 , напрямні рейки 2, по яких вільно переміщуються закріплені роликові напрямні 3 разом із рухомими столами каретки нижнім 4 і верхнім 5.

Приводиться в рух механізм каретки за рахунок зубчастої рейки 6 та з'єднаних у парі зубчастих коліс 8 і 9 (шестернязубчасте колесо) через вал 7 серводвигуна 17.

Бокові упори 18 і 19 вирівнюють книжковий блок 20. Після фіксації книжкового блока траковим транспортером, що складається 3 рами 14 та окремих ланок (траків) 15, які вільно рухаються по заданому контуру, опускається ніж 13.

У нижній частині, по обидва боки стола каретки розміщені дві напрямні опори стола каретки 12, в гніздах якої вмонтовані ролики 16. Напрямна опора 12 регулюється під заданий формат фіксатором 11 та рейкою 10.

Реверсивна подача КЖБ відбувається за рахунок серводвигуна та попередньо аналітично вибраного зубчастого механізму. Комплексно пристрій реалізує свою роботу за рахунок трьох конструктивних складових, а саме: сервопривода реверсивного типу, механізму притиску та привода механізму ножа.

Середовище автоматизованого проектування SolidWorks моделює процес транспортування КЖБ за рахунок аналітично

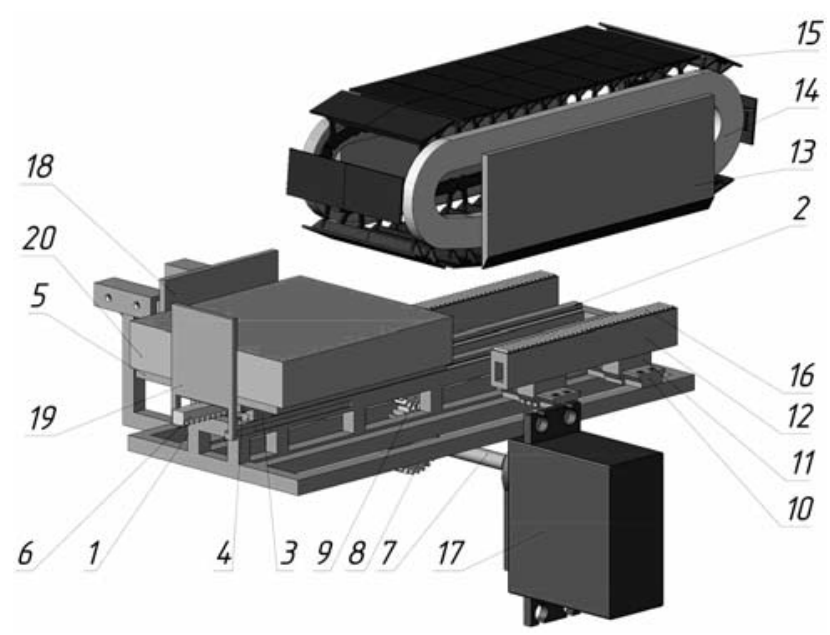

Рис. 1. Пристрій для транспортування книжкових блоків у зону їх обрізування 
визначених: потужністю двигуна $\mathrm{N}_{\text {д }}$, сил приску $\mathrm{F}_{\text {пр }}$ та різання $\mathrm{F}_{\mathrm{p}}$ книжкового блока.

Проаналізуємо функцію лінійного переміщення каретки за визначений період часу, враховуючи кінематику закону гармонійного руху:

$$
H=A \cdot \sin \left(\frac{2 \cdot \pi}{T} \cdot t_{n}+\varphi_{0}\right),
$$

де Т - період коливань, А - максимальна величина кута повороту вала двигуна, за якого відбувається транспортування каретки, фо - початкове положення вала двигуна, $t_{n}$ - час переміщення каретки.

Для дослідження механіки технологічного процесу транспортування книжкового блока виберемо три часових періоди: $\mathrm{t}_{1}=1 \mathrm{c}$, $t_{2}=1,4$ с та $t_{3}=1,8$ с (рис. 2).

За кожен вибраний часовий період (цикл) каретка повинна переміститись в зону обрізування, зупинитись для обрізування площини блока різальним інструментом та вивести його із робочої зони.

Після визначення ділильних радіусів зубчастих коліс $\mathrm{d}_{1,2}$ та їх модуля $\mathrm{m}$ - вибираємо кількість зубів зубчастого колеса $z_{1}=28$ та шестерні $z_{2}=19$. Для наших геометричних параметрів розраховане максимальне переміщення каретки пристрою становить $\mathrm{H}_{\max }=423,5 \mathrm{mм}$. Залежність лінійного переміщення каретки Н (м) від часу відображає її траєкторію в одному напрямку. Після проходження кареткою цієї відстані відбувається програмована зупинка, де відбувається технологічний процес обрізування площини книжкового блока. Конструктивно приймаємо довжину робочої зони зубчастої рейки $\mathrm{H}=450$ мм.

Для визначення лінійної швидкості каретки скористаємось залежністю:

$$
\begin{aligned}
& V_{H}=\frac{2 \cdot \pi}{T} \cdot A \cdot \cos . \\
& \cdot\left(\frac{2 \cdot \pi}{T} \cdot t_{n}+\frac{\pi}{2}\right)
\end{aligned}
$$

Враховуючи три періоди транспортування $t_{n}$, обчислюємо максимальні кінематичні показники процесу транспортування і заносимо їх у таблицю.

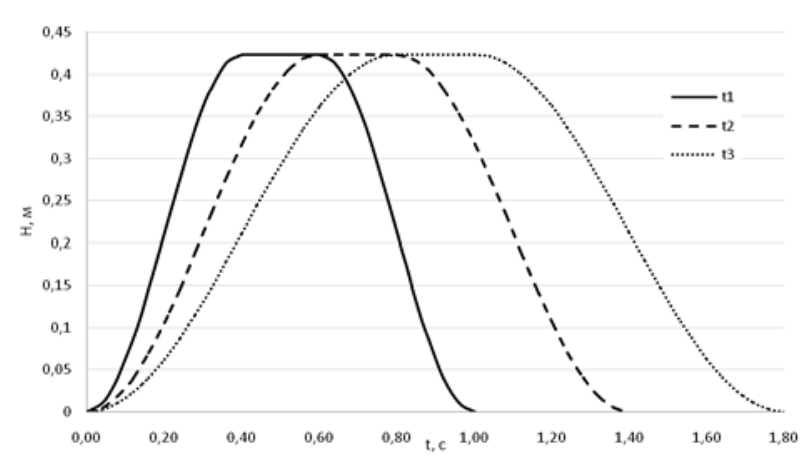

Рис. 2. Залежність лінійного переміщення каретки Н (м) від часу 
Кінематичні показники транспортування книжкового блока

\begin{tabular}{|c|c|c|c|c|}
\hline $\begin{array}{c}\text { Період транс- } \\
\text { портування }\end{array}$ & $\begin{array}{c}\text { Швидкість } \\
\text { переміщення } \\
\text { каретки }\end{array}$ & $\begin{array}{c}\text { Прискорення } \\
\text { каретки }\end{array}$ & $\begin{array}{c}\text { Частота обер- } \\
\text { тання на валу } \\
\text { двигуна }\end{array}$ & $\begin{array}{c}\text { Розрахункова } \\
\text { потужність } \\
\text { двигуна }\end{array}$ \\
\hline $\mathrm{t}_{\mathrm{n}}$, (c) & $\mathrm{V}_{\max }, \mathrm{M} / \mathrm{c}$ & $\mathrm{a}_{\max }, \mathrm{M} / \mathrm{c}^{2}$ & $\mathrm{n}_{\max }$, об/хв. & $\mathrm{N}_{\max }, \mathrm{kBт}$ \\
\hline $\mathrm{t}_{1}=1,0$ & 1,66 & 13,06 & 2022,1 & 1,11 \\
\hline $\mathrm{t}_{2}=1,4$ & 1,11 & 58,05 & 1347,9 & 0,417 \\
\hline $\mathrm{t}_{3}=1,8$ & 0,83 & 32,66 & 1011,1 & 0,397 \\
\hline
\end{tabular}

Обчислюємо і заносимо у таблицю максимальні лінійні прискорення каретки для часових періодів $t_{1}, t_{2}$ та $t_{3}$ :

$$
\begin{aligned}
& a_{H}=\left(\frac{2 \cdot \pi}{T}\right)^{2} \cdot \cos . \\
& \cdot\left(\frac{2 \pi}{T} \cdot t_{n}+\pi\right) .
\end{aligned}
$$

Та визначимо кутову швидкість на валу двигуна:

$$
\omega=\frac{\frac{2 \cdot \pi}{T} \cdot A \cdot \cos \left(\frac{2 \cdot \pi}{T} \cdot t_{n}+\frac{\pi}{2}\right)}{R},
$$

де $\mathrm{R}$ - ділильний радіус зубчастого колеса.

Сила, що потрібна для переміщення каретки:

$$
F_{\Pi}=F_{i H}+F_{n p}
$$

де $\mathrm{F}_{\mathrm{iн}}$ - інерційні сили щодо діють на каретку, $\mathrm{F}_{\text {пр }}$ - сумарна сила пружин.

Враховуючи силу, прикладену до каретки, знайдемо крутний момент на валу двигуна (з врахуванням коефіцієнта пружності пружини $\mathrm{k}=0,5)$ і відобразимо його у вигляді залежності від часу (рис. 3):

$$
M_{K}=F_{n} \cdot R=\left(F_{i H}+F_{n p}\right) \cdot R \text {. }
$$

Враховуючи часові періоди $t_{n}$ та попередні розрахункові дані, відображаємо залежності частоти обертання на валу двигуна $\mathrm{n}$ (рис. 4).

Враховуючи часовий період роботи $t_{n}$, визначимо потужність $\mathrm{N}$ на головному приводі та відобразимо розрахункові значення у таблиці, а залежність на графіку (рис. 5):

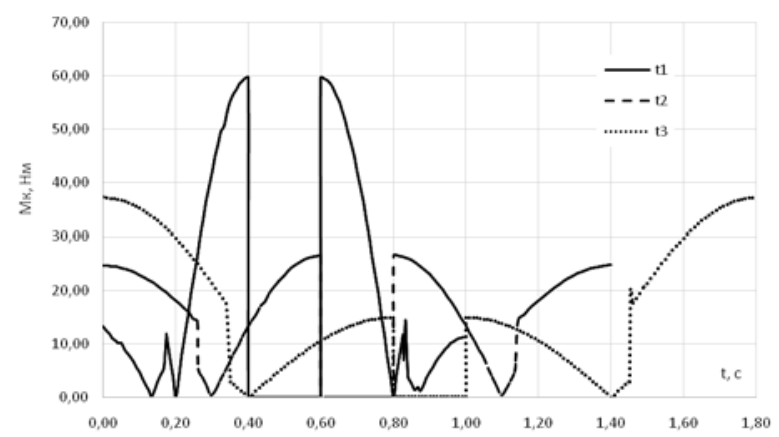

Рис. 3. Залежність крутного моменту на валу двигуна $\mathrm{M}_{\mathrm{k}}(\mathrm{HM})$ від часу $t_{n}$ 


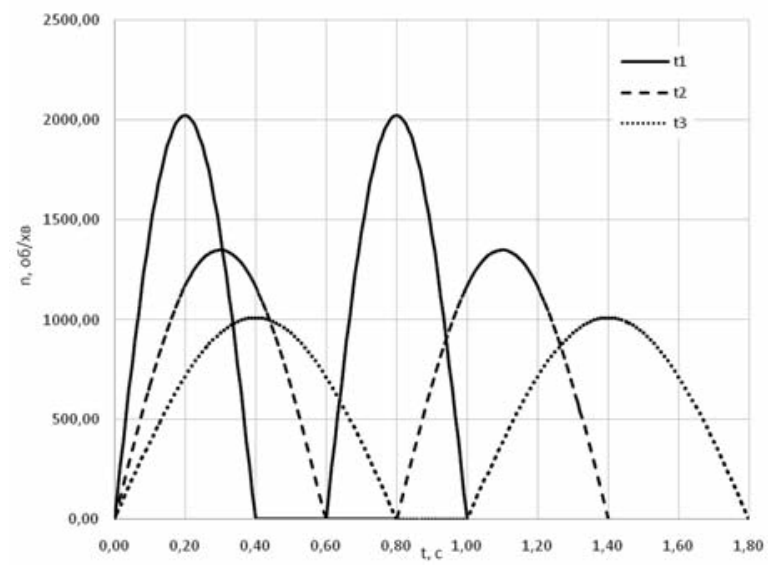

Рис. 4. Залежність частоти обертання на валу двигуна $\mathrm{n}$ (об/хв.) від $t_{1}, t_{2}$ та $t_{3}$

$$
\mathrm{N}_{\mathrm{t}_{\mathrm{n}}}=\mathrm{F}_{\mathrm{t}_{\mathrm{n}}} \cdot \mathrm{V}_{\mathrm{t}_{\mathrm{n}}}
$$

Відповідно до графіків розрахункові пікові значення припадають для $\mathrm{t}_{1}=1$ с (рис. 3-5). Наприклад, для часового проміжку $\mathrm{t}=0-0,2$ с каретка умовно починає свій рух у зону різання та набирає необхідні швидкісні показники. На графіку спостерігається крива крутного моменту, що рухаються вниз (рис. 3). Числові значення на цьому проміжку часу відносно невеликі щодо показників для $\mathrm{t}=0,2-0,4$ або $\mathrm{t}=0,3-0,6$ відповідно. Причиною цього $є$ кінематичні величини та конструктивне використання пружин стиску. Вони у вибраний момент часу згладжують пікові навантаження у двигуні. А головне, напрямок прикладених сил збігається 3 потрібним напрямком переміщення каретки.

У дослідженнях для часового періоду $t_{3}$ може спостерігатися і протилежна ситуація. Так пружина стиску може впливати на

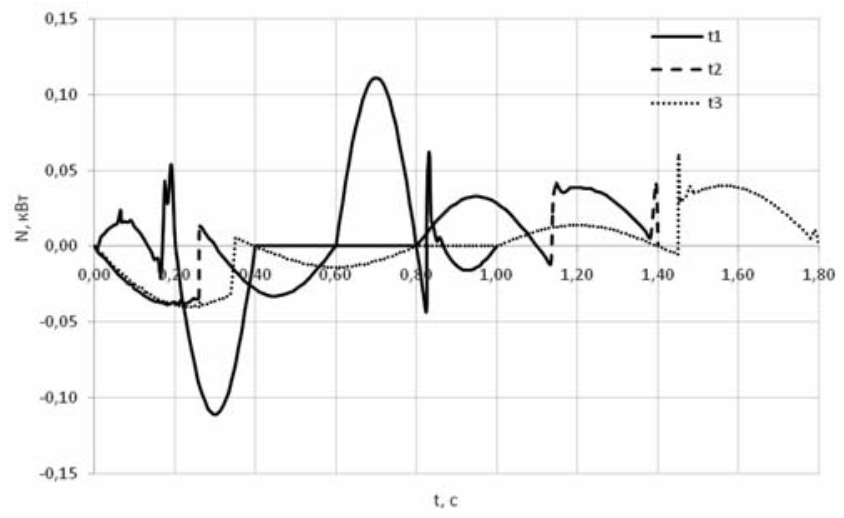

Рис. 5. Залежність потужності електродвигуна N (кВт) від періодів $t_{1}, t_{2}$ та $t_{3}$ 
каретку з силою, що перевищує силу, з якою двигун повинен її перемістити. Тому для $t_{3}$ привод двигуна «стримує» каретку від збільшення нормованої швидкості. У випадку «надмірного» споживання двигуном енергії та пікових навантажень на приводу механізмі каретки можна розмістити керовану гальмівну систему, яка б могла мінімізувати піки навантажень. Так у кінцевому проміжку часу спостерігаються перепади крутного моменту $\left(\mathrm{M}_{\mathrm{K}}\right)$, що виникають під час відокремлення каретки від переднього упору (рис. 3). У цей час сила пружини перестає впливати на каретку й двигуну потрібно самостійно приводити в рух приводні виконавчі вузли. Власне це прослідковується різким зростанням крутних моментів і досягненням максимальних значень.

На часових періодах: $t_{1}(0,4-$ $0,6 \mathrm{c}), \mathrm{t} 2(0,6-0,8 \mathrm{c})$ та $\mathrm{t} 3(0,8-1 \mathrm{c})$ у механізмі каретки спостерігається технологічна зупинка. Відбувається процес обрізування площини корінця. В наступному етапі каретка починає рух у зворотному напрямку. Помітні максимальні зміни крутних моментів до і після обрізування блока. Це пояснюється тим, що двигун вже без дії додаткових сил пружин починає сповільнювати каретку до повної її зупинки.

Відповідно до запрограмованого нами режиму роботи двигун має технологічну зупинку вистій. Крутний момент при цьому дорівнює нулю. Повернення каретки у вихідне положення відбувається під час «розгону» її двигуном. У зворотному напрямку для $\mathrm{t}_{1}(0,6-0,8 \mathrm{c})$. Так як у цьому випадку прискорення каретки $€$ максимальним (таблиця) відповідно і крутний момент на цьому проміжку теж зростає (рис. 3).

Під час руху каретки у вихідне положення спостерігається зворотній процес. Умовно каретка, набравши необхідну швидкість, починає зупинятись до моменту зустрічі з переднім упором механізму. Можна припустити, що цей процес буде супроводжуватися незначними інерційними навантаженнями. Каретка зупиняється у визначеному положенні, додатково стримуючись встановленими амортизаційними пружинами.

Під час досліджень спостерігались симетричні графіки й відносно невеликі крутні моменти. Частково це пояснюється тим, що на початку руху каретки пружини створювали додатковий тиск на неї, пришвидшували, а в кінці руху зупиняли їі.

Додавання амортизаційного механізму в якості пружин стиску в систему транспортування каретки може значно підвищити коефіцієнт корисної дії двигуна. у механізмі каретки можуть нагромаджуватися акумулятивні властивості. Спостерігаємо в часових періодах (наприклад, для $\left.\mathrm{t}_{3}\right)$, амортизаційний механізм (пружини стиску) вже навпаки створюються надлишкові навантаження на механізм. Однак вибрані кінематичні та динамічні показники не будуть перевищувати допустимі експлуатаційні режими роботи пристрою.

\section{Висновки}

Підвищення швидкісних характеристик засобів транспортування книжкових та журнальних блоків 3 одночасним точним їх 
позиціюванням у зоні обрізування дозволить збільшити продуктивність роботи потокової лінії в цілому. Використання механізму реверсивної дії зменшує габарити пристрою та мінімізує використання додаткових елементів транспортера. Пристрій легко монтується в потокову лінію або у вкладально-швейно-різальний агрегат як універсальний транспортувально-різальний модуль.

\section{Список використаної літератури}

1. Топольницький П. В. Критичний аналіз сучасного устаткування для обрізування книжково-журнальних блоків під час їх переміщення / П. В. Топольницький, С. В. Кузьма // Наукові записки. 2017. № 2(55). С. 22-29.

2. Стеців Я. Б. Удосконалення пристроїв переміщення напівфабрикатів у самонакладах поліграфічних і пакувальних машин: дис. ... канд. техн. наук: 05.05.01 / Стеців Ярослав Богданович. Львів, 2017. 193 с.

3. Приставський 3. М. Визначення кінематичних характеристик механізму клапанів ротаційного вивідного пристрою самонакладів зошитів / 3. М. Приставський, В. В. Шебунін // Технологія і техніка друкарства. 2008. Вип. 2(20). С. 110-116. Режим доступу: http://ttdruk.vpi.kpi.ua/article/view/60082.

4. Стахів Р. Б. Пристрій для перебазування книжкових блоків у машинах безвистійного тристороннього обрізування / Р. Б. Стахів // Поліграфія і видавнича справа. 1998. № 34. С. 133-137.

5. Іванко А. І. Транспортно-передавальні пристрої книжково-журнальних блоків у потоковому виробництві / А. І. Іванко, П. П. Шостачук // Технологія і техніка друкарства. 2011. Вип. 3(33). С. 96-102. Режим доступy: http://ttdruk.vpi.kpi.ua/article/view/52330.

6. Іванко А. І. Пристрій для безупинного обрізування аркушевого матеріалу в потокових лініях / А. І. Іванко, Р. В. Маржієвський // Технологія і техніка друкарства. 2012. Вип. 3(37). С. 109-113. Режим доступу: http://ttdruk.vpi.kpi.ua/article/view/32406.

7. Пат. України на кор. мод. № 80303. B26D 1/00. Пристрій для безупинного обрізування аркушевого матеріалу в потокових лініях / А. І. Іванко, Р. В. Маржієвський. Заявл. 12.11.2012; Опубл. 27.05.2013. Бюл. № 10, 2013. 4 с.

8. Маца Р. С. Удосконалення поліграфічних машин шляхом застосування комбінованих циклових важільних механізмів з програмованою зміною довжини шатуна: дис. ... канд. техн. наук: 05.05.01 / Роман Степанович Маца. Львів, 2012. 169 с.

9. Пат. України № 104796 C2. B42D 1/00. Пристрій для транспортування зошитів на хитний стіл ниткошвейного автомата / Ю. Й. Хведчин, І. І. Регей, О. Б. Книш. Заявл. 11.09.2012; Опубл. 11.03.2014. Бюл. № 5, 2014. 4 с.

10. Пат. України № 103240 С2. В65B 41/00. Пристрій для переміщення плоских напівфабрикатів / О. М. Полюдов, І. І. Регей, А. Б. Коломієць, Я. Б. Стеців. Заявл. 28.11.2011. Опубл. 25.09.2013. Бюл. № 18, 2013. 4 с.

11. Пат. України № 117019 С2. В65В 41/08. Пристрій для переміщення плоских напівфабрикатів / І. І. Регей, А. Б. Коломієць, В. О. Кузнецов. Заявл. 08.02.2016. Опубл. 11.06.2018. Бюл. № 11, 2018. 4 с.

12. Іванко А. І. Обрізування аркушевих матеріалів у пневматичних транспортувальних системах / А. І. Іванко, О. С. Марченко // Технологія і техніка друкарства. 2016. Вип. 2(52). С. 72-78. DOI: https://doi.org/10.20535/20777264.2(52).2016.71012. 
13. Ivanko A. Cardboard sheet cutting with air-operated conveying devices using / A. Ivanko // International research and practice conference 'Modern methods, innovations, and experience of practical application in the field of technical sciences'. Radom Academy of Economics. Radom, Republic of Poland; 27.12.2017. P. 116-119.

14. Ivanko A. Pneumatic transportation systems of sheet material / A. Ivanko, O. Marchenko // VII International scientific conference 'Advanced technologies in mechanical engineering', Institute of Engineering Mechanics and Transport / Lviv Polytechnic National University. Lviv-Zveniv, 5-9 February 2018. P. 15-17.

\section{References}

1. Topolnytskyi, P. V. \& Kuzma, S. V. (2017). Krytychnyi analiz suchasnoho ustatkuvannia dlia obrizuvannia knyzhkovo-zhurnalnykh blokiv pid chas iikh peremishchennia. Journal of Naukovi zapysky, 2(55), 22-29 [in Ukrainian].

2. Stetsiv, Ya. B. (2017). Udoskonalennia prystroiv peremishchennia napivfabrykativ u samonakladakh polihrafichnykh i pakuvalnykh mashyn. Lviv, 193 p. [in Ukrainian].

3. Prystavskyi, Z. M. \& Shebunin, V. V. (2008). Vyznachennia kinematychnykh kharakterystyk mekhanizmu klapaniv rotatsiinoho vyvidnoho prytsroiu samonakladiv zoshytiv. Journal of Tekhnolohiia i tekhnika drukarstva, 2(20), 110-116. Retrieved from http://ttdruk.vpi.kpi.ua/article/view/60082 [in Ukrainian].

4. Stakhiv, R. B. (1998). Prystrii dlia perebazuvannia knyzhkovykh blokiv u mashynakh bezvystiinoho trystoroniioho obrizuvannia. Journal of Polihrafiia $i$ vydavnycha sprava, 34, 133-137 [in Ukrainian].

5. Ivanko, A. I. \& Shostachuk, P. P. (2011). Transportno-peredavalni prystroi knyzhkovo-zhurnalnykh blokiv u potokovomu vyrobnytstvi. Journal of Tekhnolohiia i tekhnika drukarstva, 3(33), 96-102. Retrieved from http://ttdruk.vpi.kpi.ua/article/view/52330 [in Ukrainian].

6. Ivanko, A. I. \& Marzhiievskyi, R. V. (2012). Prystrii dlia bezupynnoho obrizuvannia arkushevoho materialu v potokovykh liniiakh. Journal of Tekhnolohiia i tekhnika drukarstva, 3(37), 109-113. Retrieved from http://ttdruk.vpi.kpi.ua/ article/view/32406 [in Ukrainian].

7. Ivanko, A. I. \& Marzhiievskyi, R. V. Prystrii dlia bezupynnoho obrizuvannia arkushevoho materialu v potokovykh liniiakh // Patent № 80303. Ukraine. B26D 1/00. Publish 27.05.2013 [in Ukrainian].

8. Matsa, R. S. (2012). Udoskonalennia polyhrafichnykh mashyn shliakhom zastosuvannia kombinovanykh tsyklovykh vazhilnykh mekhanizmiv z prohramovanoiu zminoiu dovzhyny shatuna. Lviv, 169 p. [in Ukrainian].

9. Khvedchyn, Yu. Io. \& Rehei, I. I. \& Knysh, O. B. Prystrii dlia transportuvannia zoshytiv na khytnyi stil nytkoshveinoho avtomata // Patent № 104796 C2. Ukraine. B42D 1/00. Publish 11.03.2014 [in Ukrainian].

10. Poliudov, O. M. \& Rehei, I. I. \& Kolomiiets, A. B. \& Stetsiv, Ya. B. Prystrii dlia peremishchennia ploskykh napivfabrykativ // Patent № 103240 C2. Ukraine. B65B 41/00. Publish 25.09.2013 [in Ukrainian].

11. Rehei, I. I. \& Kolomiiets, A. B. \& Kuznetsov, V. O. Prystrii dlia peremishchennia ploskykh napivfabrykativ // Patent № 117019 C2. Ukraine. B65B 41/08. Publish 11.06.2018 [in Ukrainian]. 
12. Ivanko, A. I. \& Marchenko, O. S. (2016). Obrizuvannia arkushevykh materialiv u pnevmatychnykh transportuvalnykh systemakh. Journal of Tekhnolohiia i tekhnika drukarstva, 2(52), 72-78. DOI: https://doi.org/10.20535/20777264.2(52).2016.71012 [in Ukrainian].

13. Ivanko, A. (2017). Cardboard sheet cutting with air-operated conveying devices using. Journal of International research and practice conference 'Modern methods, innovations, and experience of practical application in the field of technical sciences', 116-119. Radom [in English].

14. Ivanko, A. \& Marchenko, O. (2018). Pneumatic transportation systems of sheet material. Journal of International scientific conference 'Advanced technologies in mechanical engineering', 15-17. Lviv-Zveniv [in English].

В статье проведено компьютерное моделирование
в среде SolidWorks приспособления для транспорти-
ровки книжных и журнальных блоков в зону их обрезки.

Ключевые слова: книжно-журнальный блок; обрезка; траковый транспортер; серводвигатель; траектория движения; сервопривод; поточная линия.

The article contains computer simulations in the SolidWorks environment of a device for transporting book and magazine blocks to their trimming area.

Keywords: book-journal block; trimming; truck conveyor; servomotor; trajectory of movement; servo drive; production line.

Рецензент - О. О. Палюх, канд. техн. наук, доцент, КПІ ім. Ігоря Сікорського 